\title{
Terahertz Pulsed Imaging Reveals the Stratigraphy of a Seventeenth-Century Oil Painting
}

\author{
A. Locquet*a,b J. Dong ${ }^{\mathrm{a}, \mathrm{b}}$, M. Melis ${ }^{\mathrm{c}}$, and D. S. Citrin ${ }^{\mathrm{a}, \mathrm{b}}$ \\ aUnité Mixte Internationale 2958 Georgia Tech-CNRS, Georgia Tech Lorraine, \\ 2 Rue Marconi, 57070 Metz, France \\ ${ }^{\mathrm{b}} \mathrm{School}$ of Electrical and Computer Engineering, Georgia Institute of Technology, \\ 30332-0250, Atlanta, Georgia, USA \\ 'Profilocolore srl, Via Spluga, 2200141 Roma, Italy
}

\begin{abstract}
Terahertz pulsed imaging has attracted considerable interest for revealing the stratigraphy and hidden features of art paintings. The reconstruction of the stratigraphy is based on the precise extraction of $\mathrm{THz}$ echo parameters from the reflected signals. Several historical panel paintings and wall paintings have been well studied by THz reflective imaging, in which the detailed stratigraphy has been successfully revealed. To our knowledge, however, the stratigraphy of oil paintings has not been clearly uncovered by $\mathrm{THz}$ imaging, since the paint layers in an oil painting on canvas, especially for the $16^{\text {th }}$ and $17^{\text {th }}$ century art works, are usually very thin $(\sim 10 \mu \mathrm{m})$ in the $\mathrm{THz}$ regime. Therefore, in order to improve the performance of $\mathrm{THz}$ imaging, advanced signal-processing techniques with higher depth-resolution are still needed. In this study, THz reflective imaging is employed to reveal for the first time the detailed stratigraphy of a 17 th century Italian oil painting on canvas. The paint layers on the supporting canvas are very thin in the $\mathrm{THz}$ regime, as the $\mathrm{THz}$ echoes corresponding to the stratigraphy totally overlap in the first cycle of the reflected $\mathrm{THz}$ signal. $\mathrm{THz}$ sparse deconvolution based on an iterative shrinkage algorithm is utilized to resolve the overlapping echoes. Based on the deconvolved signals, the detailed stratigraphy of this oil painting on canvas, including the varnish, pictorial, underdrawing, and ground layers, is successfully revealed. The THz C- and B-scans based on the THz deconvolved signals also enable us to reveal the features of each layer. Our results thus enhance the capability of terahertz imaging to perform detailed analysis and diagnostics of historical oil paintings on canvas with foreseen applications for the study of the artist's technique and for authentication.
\end{abstract}

Keywords: Terahertz imaging, terahertz time-domain spectroscopy, art painting, stratigraphic analysis, sparse signals, sparse deconvolution

\section{INTRODUCTION}

Terahertz time-domain spectroscopy (THz TDS) provides a nondestructive and noncontact technique for characterizing materials. THz waves can penetrate a variety of nonpolar materials which are opaque in the range of visible and infrared light. THz imaging can provide information in depth to investigate works of art, which is of great interest for conservation and restoration, as well as for art-historical studies. In recent years, THz imaging has shown great potential in the cultural-heritage arena [1-9]. In particular, $\mathrm{THz}$ has been successful in identifying features hidden under the surface of a painting, such as the artist's signature [10] or under-drawings [11-14]. Even in the case in which no underdrawing is present, identifying the stratigraphic structure of an art painting is useful in the study of the painter's technique. The objective of this study is to apply to apply $\mathrm{THz}$ reflective imaging to reveal the stratigraphy and hidden features the 17th century easel painting Madonna in Preghiera by the workshop of Giovanni Battista Salvi da Sassoferrato, represented in Fig. 1, together with UV fluorescence and IR reflectography images. The dimensions of this painting are $24 \mathrm{~cm}$ by $32 \mathrm{~cm}$. The canvas is mounted on a wood stretcher. Visually, the paint application itself is smooth and uniform, though subsequently formed craquelure or other inclusions in the canvas give rise to nonuniform features in the surface texture.

*alocquet@georgiatech-metz.fr 
A typical THz time-domain system (Teraview TPS Spectra 3000) is employed in this study. The GaAs photoconductive antenna is excited by an ultrafast laser to produce roughly single-cycle THz pulses with bandwidth extending from 60 $\mathrm{GHz}$ to $3 \mathrm{THz}$. The maximum peak of its power spectrum is located at about $0.3 \mathrm{THz}$. The focus spot size of the THz beam is frequency-dependent, and is about $300 \mu \mathrm{m}$ at $1 \mathrm{THz}$.

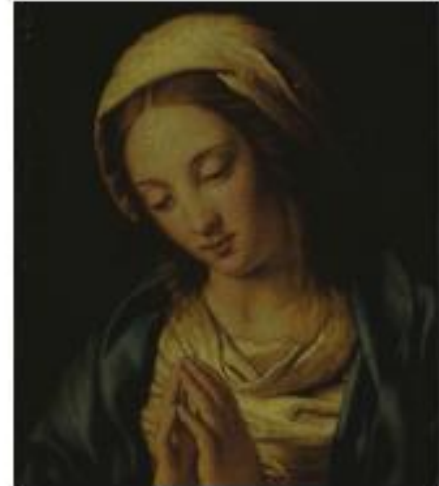

(a)

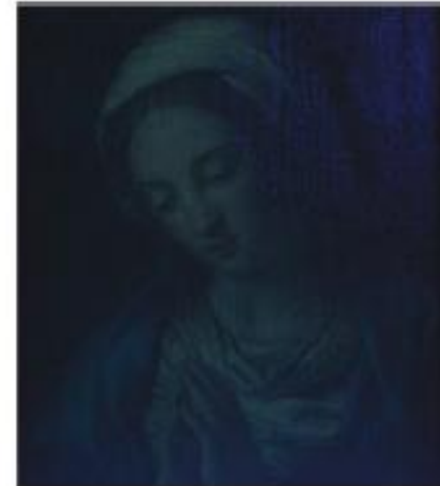

(b)

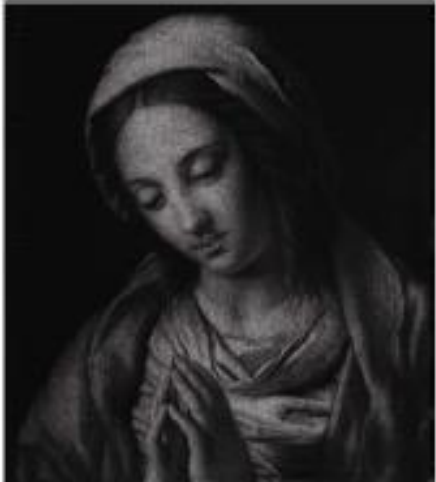

(c)

Figure 1(a) Visible photograph of the Madonna in Preghiera, (b) UV Fluorescence Image, and (c) IR Reflectography Image.

\section{SPARSITY-BASED DECONVOLUTION}

The detailed stratigraphy associated with the painting itself is not evident in the raw data obtained by raster-scanning the surface of the painting. Sparsity-based time-domain deconvolution based on the shrinkage algorithm is utilized to process the 3D volume raw data, as described in Ref. [15]. After deconvolution, a sparsity-based impulse-response function is achieved, which entirely depends on the stratigraphy and provides a new imaging domain with enhanced depth resolution. The sparsity-based impulse-response function, which consists of a baseline at zero and then a sequence of sharp peaks, enables us to reconstruct the detailed stratigraphy of the painting. By performing a peak-detection (both positive and negative peaks), binary THz B-scans, in which a valid peak is assigned value ' 1 ' and the other positions ' 0 ' regardless of the sign or height of the peak, can be obtained. The binary THz B-scan with the cross-section $Y=150$ is shown in Fig. 2(b). The comparison with the THz B-scan based on the raw signals in Fig. 2(a), shows that the binary $\mathrm{THz}$ B-scan unlocks a wealth of information absent in the raw B-scan. It reveals, for the first time based on $\mathrm{THz}$ reflectometry, the detailed stratigraphy above the supporting canvas of a 17 th century easel painting, as described in the following section. 

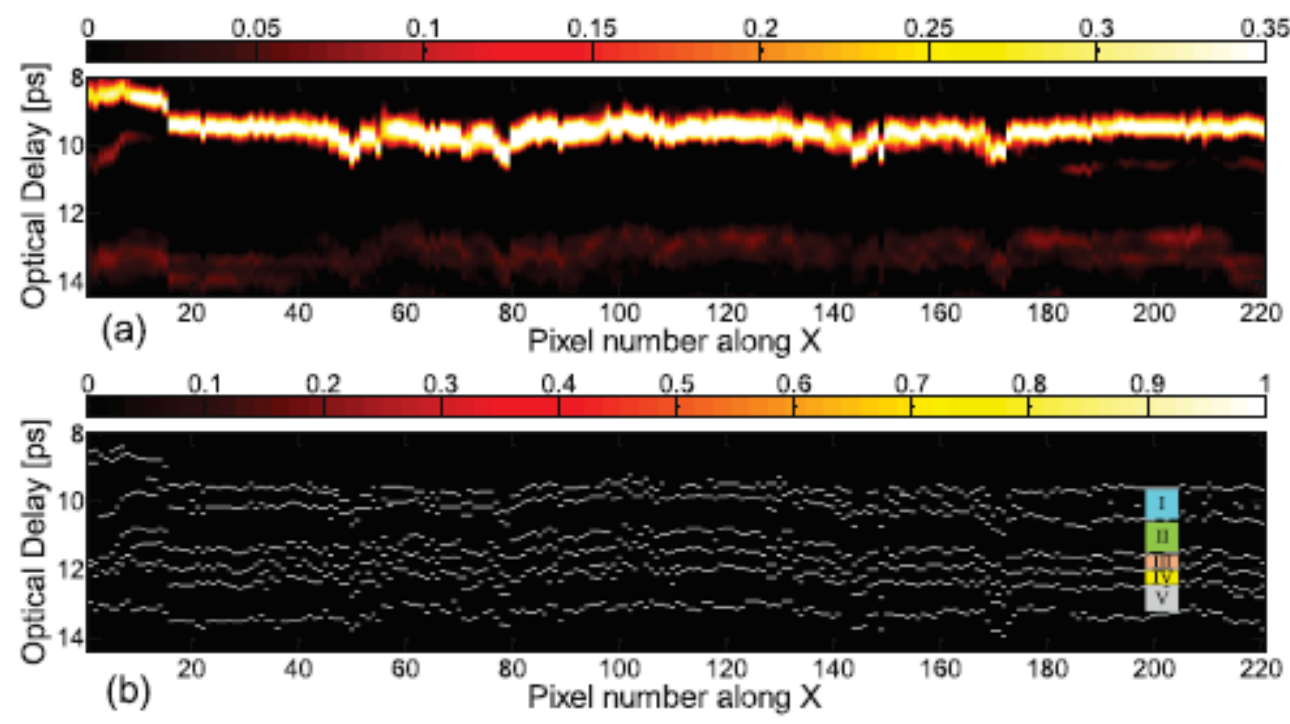

Figure 2. (a)THz B-scan based on the raw measured data and (b) Binary THz B-scan based on the deconvolved data for a typical cross-section, in which a valid peak is assigned value ' 1 ' and the other positions ' 0 ' regardless of the sign or height of the peak. I: varnish; II: pictorial layer; III: underpainting; IV: imprimatura; V: ground layer.

\section{RESULTS AND DISCUSSION}

Sparsity-based THz reflectometry provides detailed 3D information on the 10- $\mu m$-to-mm scale in the depth direction and the 100-of- $\mu m$-to- $m$ scale in the transverse directions, enabling us to reconstruct the detailed stratigraphy of the Madonna in Preghiera. Quantitative information in depth, such as the physical thicknesses of each resolved layer, can be estimated based on the knowledge of corresponding refractive indices. Starting with the canvas, a ground layer (gesso) is applied to seal the canvas and to create a smooth surface on which to paint, shown as layer V in Fig. 2(b). The imprimatura (layer IV) follows the ground that would seal the oil-absorbent layer. Without the imprimatura, paint directly applied would soak into the ground and be difficult to control. The underpainting layer (layer III) provides a proper foundation of the scene/subject matter, which was typically painted in a dark and muted monochrome tone, usually consisting of umber, as brown underpainting has often be used in oil painting from the 15th to 17th centuries. Such an approach was widespread to the point that the entire tonality and compositions of paintings frequently accounted for this dark underpainting. THz B- and C-scans clearly reveal the features of the ground, imprimatura, and the underpainting layers, which are fairly uniform across the painting. Assuming the refractive index of gesso is about 1.52 [16], the average physical thickness of the ground layer is about $132.7 \mu \mathrm{m}$. For other oil-based paint layers, although the difference of refractive index between each layer is sufficient to produce the $\mathrm{THz}$ reflections, we assume a mean refractive index of 1.85 [16] in order to estimate the physical thickness of each paint layer. Based on this assumed refractive index, we estimate the average thickness of imprimatura is $\sim 34 \mu \mathrm{m}$ and the average thickness of the underpainting layer is $\sim 38 \mu \mathrm{m}$. The presence of these three preparatory layers is confirmed by optical microscopy near the painting's edge, where these layers are exposed.

The pictorial layers (region II in Fig. 2(b)) are applied subsequent to the underpainting. They contain the visually evident composition of the finished painting, and consist of additional applications of background color, the figure of the Madonna, facial features, hands, the gossamer veil, and other fine details. In $\mathrm{THz} \mathrm{C}$-scans, textural features due to the craquelure first become pronounced in the pictorial layer. This is also where we observe the presence of delamination, closely associated with the craquelure. It was typical in the 17 th century finally to apply varnish (a natural resin) to saturate the paint colors and protect the surface (layer I). The craquelure continues to be pronounced in the varnish, as is evidenced in the corresponding $\mathrm{THz} \mathrm{C}$-scans. The application of the varnish is not uniform across the painting. Assuming the refractive index of the varnish is about 1.6 [17], the physical thickness of the varnish at pixel $(89,150)$ is about $35 \mu \mathrm{m}$.

In summary, sparsity-based $\mathrm{THz}$ reflectometry presented in this study clearly revealed the detailed stratigraphy of a 17 th century easel painting with layer thicknesses less than $50 \mu \mathrm{m}$, including the varnish, pictorial, underpainting, 
imprimatura, and the ground layers across the entire painting. The results achieved by sparsity-based THz reflectometry are supported by an optical microscopy analysis in a region where the layers are exposed. We have demonstrated that sparsity-based $\mathrm{THz}$ reflectometry promises to provide an effective in-situ 3D quantitative imaging modality with high depth resolution and dynamic range for a broad range of cultural heritage objects, and an invaluable contribution to arthistorical studies, as well as for conservation, restoration, and authentication.

\section{ACKNOWLEDGMENTS}

A.L, J.D., and D.S.C thank the financial support of the Fonds Européen de Développement Régional, the Conseil Régional Grand Est, and the CPER SusChemProc.

\section{REFERENCES}

[1] J. B. Jackson, J. Bowen, G. Walker, J. Labaune, G. Mourou, M. Menu, and K. Fukunaga, “A survey of terahertz applications in cultural heritage conservation science," IEEE Trans. THz Sci. Technol. 1, 220-231 (2011).

[2] K. Krügener, M. Schwerdtfeger, S. F. Busch, A. Soltani, E. Castro-Camus, M. Koch, and W. Viöl, "Terahertz meetssculptural and architectural art: Evaluation and conservation of stone objects with T-ray technology," Sci. Rep. 5, 14842 (2015).

[3] M. Koch, S. Hunsche, P. Schumacher, M. C. Nuss, J. Feldmann, and J. Fromm, "THz-imaging: a new method for density mapping of wood," Wood Sci. Technol. 32, 421-427 (1998).

[4] J. B. Jackson, M. Mourou, J. Labaune, J. F. Whitaker, I. N. Duling III, S. L.Williamson, C. Lavier, M. Menu, and G.A. Mourou, "Terahertz pulse imaging for tree-ring analysis: a preliminary study for dendrochronology applications," Meas. Sci. Technol. 20, 075502 (2009).

[5] J. Labaune, J. B. Jackson, K. Fukunaga, J. White, L. D’Alessandro, A. Whyte, M. Menu, and G. Mourou, "Investigation of Terra Cotta artefacts with terahertz," Appl. Phys. A 105, 5-9 (2011).

[6] J. Labaune, J. B. Jackson, S. Pagès-Camagna, I. N. Duling III, M. Menu, and G. A. Mourou, "Papyrus imaging with terahertz time domain spectroscopy," Appl. Phys. A 100, 607-612 (2010).

[7 ] L. Öhrström, B. M. Fischer, A. Bitzer, J. Wallauer, M. Walther, and F. Rühli, "Terahertz imaging modalities of ancient Egyptian mummified objects and of a naturally mummified rat," The Anatomical Record 298, 11351143 (2015).

[8] J. B. Jackson, J. Labaune, R. Bailleul-Lesuer, L. D’Alessandro, A. Whyte, J. W. Bowen, M. Menu, and G. Mourou,"Terahertz pulse imaging in archaeology," Frontiers of Optoelectronics 8, 81-92 (2015).

[9] C. Seco-Martorell, V. López-Dominguez, G. Arauz-Garofalo, A. Redo-Sanchez, J. Palacios, and J. Tejada, “Goya's artwork imaging with Terahertz waves," Opt. Express 21, 17800-17805 (2013).

[10] J. Dong, J.B. Jackson, M. Melis, D. Giovanacci, G.C. Walker, A. Locquet, J.W. Bowen, and D.S. Citrin, "Terahertz frequency-wavelet domain deconvolution for stratigraphic and subsurface investigation of art painting", Opt. Express 24, 26972 (2016).

[11] C. L. Koch-Dandolo, T. Filtenborg, K. Fukunaga, J. Skou-Hansen, and P. U. Jepsen, "Reflection terahertz time domain imaging for analysis of an 18th century neoclassical easel painting," Appl. Opt. 54, 5123-5129 (2015).

[12] C. L. Koch-Dandolo, T. Filtenborg, J. Skou-Hansen, and P. U. Jepsen, “Analysis of a seventeenth-century panelvpainting by reflection terahertz time-domain imaging (THz-TDI): contribution of ultrafast optics to museum collections inspection," Appl. Phys. A 121, 981-986 (2015).

[13] C. L. Koch-Dandolo, and P. U. Jepsen, "Wall painting investigation by means of non-invasive terahertz timedomain imaging (THz-TDI): Inspection of subsurface structures buried in historical plasters," J. Infrared Millim. Te. 37, 198-208 (2016).

[14] K. Fukunaga, T. Ikari, and K. Iwai, "THz pulsed time-domain imaging of an oil canvas painting: a case study of a painting by Pablo Picasso," Appl. Phys. A 122, 106 (2016).

[15] Dong, J., Wu, X., Locquet, A. \& Citrin, D. S. Terahertz Superresolution Stratigraphic Characterization of Multilayered Structures Using Sparse Deconvolution. IEEE Trans. Terahertz Sci. Technol. 7, 260-267 (2017).

[16] Gomez-Sepulveda, A. M. et al. History of Mexican Easel Paintings from an Altarpiece Revealed by Noninvasive Terahertz Time-Domain Imaging. J. Infrared, Millimeter, Terahertz Waves 38, 403-412 (2017).

[17] Yun-Sik, J., Geun-Ju, K. \& Seok-Gy, J. Terahertz Dielectric Properties of Polymers. Journal of Korean Physical Society 49, S. 513 (2006). 